\section{Focus on fleas}

Harry Hoogstraal

The Rothschild Collection of Fleas: The

Ceratophyllidae.

By Robert Traub, Miriam Rothschild and John Haddow.

Published privately (distributed by Academic Press): 1983. Pp.494. £60, $\$ 99$.

WE have here a contradiction to the statement: "No great and enduring volume can ever be written on the fleas, though many there be who have tried it" ( $\mathrm{H}$. Melville in Moby Dick, Chapter 104). Preceded by five volumes of the Illustrated Catalogue of Fleas (Siphonaptera) in the British Museum (Natural History), this review of the Ceratophyllidae has been particularly difficult and time-consuming to prepare. Since 1936, when the last critical review of the family was published, the number of component species has increased from 71 to about 470 in 65 genera and subgenera, or about $20 \%$ of all known fleas.

As in the previous volumes, the specimens in the Rothschild and British Museum collections are listed. However, because of the sheer number of ceratophyllid species, the format of this volume differs from that of the first five. The keys (by F.G.A.M. Smit) to genera and subgenera (seven genera and eight subgenera are described as new) are preceded by a detailed account of morphology and a table of comparative morphology of the closely related family Leptopsyllidae, and are illustrated by 205 line-drawings and 90 photomicrographs (by J. Navarro and R. Traub) of definitive structures of each genus.

The sections on zoogeography and distribution, and the notes on hosts, include comments on the ecology of each ceratophyllid species. A distribution map accompanies the introductory remarks for each genus. The 151 full-page maps show collecting localities of each species on a background of the distribution of the chief host - a formidable task for much of the world, when dealing with so many different flea and host species from so many remote localities.

The review of hosts of ceratophyllids is a classic exposition of host-parasite relationships, special reference being made to the historical distribution of the chief hosts (especially the more-recently evolved Sciuridae, Cricetidae, Geomyidae; and certain birds). It appears to me that the nesting types of many important avian hosts (woodpeckers, swallows, weaver birds, buntings and so on) of ceratophyllids may have a significant role in their infestations by these fleas. The reasoning ("'negative evidence") for the dearth of ceratophyllids on Muridae, other rodents and mammals of other orders is as important for biologists to understand as the reasons advanced for why

mia, other bacterial infections, rickettsiae, viruses, and other infections and medical aspects.

Three appendices complete the book, the first listing species described since 1975 , the second dealing with the orders of hosts (and the number of families, genera and species in each) and the number of ceratophyllids (genera/subgenera) and other flea families associated with these host orders and families. Finally, Appendix 3 is an alphabetical list of host genera together with the major ceratophyllid species infesting each.

In the preface, the authors state that their aim was to provide a sound base for future work on this family of parasites and to assist the medical entomologist in the task of identifying his specimens. They have amply fulfilled their mission, and have contributed much solid data and conceptual wisdom to the biomedical sciences.

Harry Hoogstraal is Senior Scientist at the US Naval Medical Research Unit No.3, Cairo, Egypt, and President-elect of the American Society of Parasitologists.

\section{Policy for science}

\section{Harvey Brooks}

Science in Government: A Review of the Principles and Practice of Science Policy. By J. Ronayne.

Edward Arnold: 1984. Pp.250.

Pbk £9.95, \$19.95.

FOR the reader familiar with recent writings on science policy, there are few surprises or new insights in this book. However, it is an excellent and comprehensive review of a diverse and scattered literature - I know of no other book where this material has been brought together in such an organized and coherent way.

Ronayne interprets the term "science policy" as "policy for science"; there is little discussion of the use of science to inform political decisions about nonscientific issues - what is usually termed "science for policy". He deals with how national governments are or should be organized to support scientific research and development; the theory and practice of determining priorities among areas of research; the pervasive tensions between the claims of the scientific community for autonomy and the demands of society or the political system for accountability; the rationales for government intervention or non-intervention in the industrial innovation system; the role of science policy in fostering industrial innovation and economic growth, and the contribution of basic research to the economy; and the relative merits of centralized and decentralized (or pluralistic) approaches to science policy.

In the accountability versus autonomy debate, Ronayne concludes that society should determine the broad goals of research and areas of emphasis, while leaving questions of tactics and execution to the scientific community. On the question of scientific priorities, he is sceptical of the value of formalized analytical techniques of assessment, except possibly as an indirect stimulus to more systematic thought about opportunities and needs. $\mathrm{He}$ quotes with approval a University of Sussex dictum that "cost-benefit studies should not be undertaken... when the results may be taken seriously". Finally, on centralism versus pluralism, he seems to recommend a middle course, somewhat biased towards a semi-centralized position, in which "countries employ their scientists and technologists in a concerted manner to attack the problems that emerged in the new economic context"'.

Most of what is available in the literature consists either of advocacy or of multiauthored collections in which no attempt is made to contrast and analyse various perspectives. In addition to providing a comparative view, the book contains excellent descriptions of the government organization for science sponsorship and science policy in most of the major industrialized countries. It should thus provide a valuable textbook for an introductory course in science policy, and it deserves a wide audience. One unique feature is the first chapter, which presents a condensed history of the evolution of science policy from the beginnings of modern science in the seventeenth century; I found this the most original aspect of the book.

Harvey Brooks is Benjamin Peirce Professor of Technology and Public Policy at Harvard University. 